Check for updates

Cite this: RSC Adv., 2019, 9, 7984

Received 15th February 2019

Accepted 5th March 2019

DOI: 10.1039/c9ra01186b

rsc.li/rsc-advances

\section{Two-dimensional additive diethylammonium iodide promoting crystal growth for efficient and stable perovskite solar cells $\dagger$}

\author{
Xin Huang, Qiuhong Cui, (DD * Wentao Bi, Ling Li, Pengcheng Jia, Yanbing Hou, \\ Yufeng Hu, (D) Zhidong Lou (D) and Feng Teng*
}

\begin{abstract}
Methylammonium lead iodide perovskite photovoltaics have attracted remarkable attention due to their exceptional power conversion efficiencies (PCEs). The film morphology of organometallic halide perovskite plays a very important role in the performance of planar perovskite solar cells (PVSCs). Previous methods have been explored to control the crystal growth for getting a compact and smooth perovskite film. Here, we report an effective and reproducible approach for enhancing the stability and the efficiency of PVSCs by incorporating a small quantity of two-dimensional (2D) material diethylammonium iodide (DAI) in three-dimensional (3D) MAPb| 3 , which can facilitate the perovskite crystallization processes and improve the resulting film crystal quality. The fabricated $\left(\mathrm{DA}_{2} \mathrm{Pbl}_{4}\right)_{0.05} \mathrm{MAPb}_{3}$ perovskite hybrid films exhibit good morphology with larger grains and uniform morphology. Simultaneously, reduced defects and enhanced carrier lifetime within a full device indicate enhanced crystallization effects as a result of the DAI inclusion. The photovoltaic device attains a high photocurrent of $22.95 \mathrm{~mA} \mathrm{~cm}{ }^{-2}$ and a high fill factor of $79.04 \%$, resulting in an overall PCE of $19.05 \%$. Moreover, the stability of the $10 \%$ DAI doped perovskite solar cell is also improved. These results offer a promising stable and efficient light-absorbing material for solid-state photovoltaics and other applications.
\end{abstract}

\section{Introduction}

Organic-inorganic metal halide perovskite solar cells (PVSCs) represent a breakthrough for next generation thin-film optoelectronics due to their outstanding properties such as high absorption coefficient, ${ }^{1,2}$ long electron-hole diffusion lengths, ${ }^{3,4}$ tunable bandgap, ${ }^{5-7}$ and low-temperature processability, ${ }^{8}$ which bring about the promise of both high efficiency and low fabrication cost, ${ }^{3,9}$ and have already improved power conversion efficiency (PCE) from $3.8 \%$ to $23.7 \%$. $^{\mathbf{1} 10}$ Theoretically speaking, the PVSCs may achieve an excellent PCE about $31 \%$ with high fill factor $(\mathrm{FF})$ and open circuit voltage $\left(V_{\mathrm{OC}}\right){ }^{11}$ Many strategies to improve the quality of perovskite films for high FF have been applied, including one-step spin coating, ${ }^{12}$ antisolvent dripping, ${ }^{13}$ two-step sequential deposition, ${ }^{14}$ vapor deposition, ${ }^{15}$ doctor blading ${ }^{16}$ and various improved strategies. Among them, a solution-processed perovskite film deposition procedure and antisolvent dripping method has become popular method, due to its fast film growth technique. The narrow processing

Key Laboratory of Luminescence and Optical Information, Ministry of Education, Beijing Jiaotong University, Beijing 100044, China. E-mail: qhcui@bjtu.edu.cn; fteng@bjtu.edu.cn; Tel: +8610 51684860

$\dagger$ Electronic supplementary information (ESI) available. See DOI: 10.1039/c9ra01186b window for properly adding the antisolvent makes it tricky to fabricate high quality perovskite film. For guaranteeing the improved morphology of the perovskites, additional operations like thermal treatment, ${ }^{17}$ solvent annealing, ${ }^{18}$ or using additives $^{19-21}$ have been adopted. Several types of chemical additives, such as polymers, ${ }^{22}$ ionic liquids ${ }^{23}$ and ammonium salts ${ }^{24,25}$ can increase the performance of PVSC devices.

Two-dimensional (2D) materials have become popular ronment due to their unique structure characterized by hydrophobic groups which are combined with $3 \mathrm{D}$ perovskite in PVSCs. ${ }^{26,27} 2 \mathrm{D}$ perovskites $\mathrm{PEA}_{2} \mathrm{MA}_{2} \mathrm{~Pb}_{3} \mathrm{I}_{10}$ (PEA = $\left.\mathrm{C}_{6} \mathrm{H}_{5}\left(\mathrm{CH}_{2}\right)_{2} \mathrm{NH}_{3}\right)^{28}$ and $\mathrm{BA}_{2} \mathrm{MA}_{n-1} \mathrm{~Pb}_{n} \mathrm{I}_{3 n+1}\left(\mathrm{BA}=\mathrm{CH}_{3}\left(\mathrm{CH}_{2}\right)_{3} \mathrm{NH}_{3}\right.$, $n=2,3$, and 4), ${ }^{29}$ and quasi-2D perovskites $\mathrm{PEA}_{2} \mathrm{MA}_{59} \mathrm{~Pb}_{60} \mathrm{I}_{181},{ }^{30}$ and $(\mathrm{BE})_{2}(\mathrm{FA})_{8} \mathrm{~Pb}_{9} \mathrm{I}_{28},{ }^{31}\left(\mathrm{BE}=\mathrm{C}_{6} \mathrm{H}_{5} \mathrm{CH}_{2} \mathrm{NH}_{3}\right)$ were used as active layers and significantly improved the moisture stability of PVSCs. The devices based on the above layered perovskite compounds exhibit a slightly lower PCE than the control device owing to the introduction of insulated spacer cations in the 3D perovskite lattice, which have strongly bound excitons with low mobility that may hamper the charge transport in perovskite films..$^{28,29,32,33}$ Thus, recent attempts have been focused on introducing small quantity of two-dimensional (2D) materials to fabricate perovskite film. ${ }^{34,35}$ A small quantity of PEAI were used to fabricate $\left(\mathrm{PEA}_{2} \mathrm{PbI}_{4}\right)_{0.017}\left(\mathrm{MAPbI}_{3}\right)$ PVSCs with highly ammonium salts attributed to great tolerance to moist envi- 
efficiency and long-term-stable, while the exist of $\mathrm{PEA}_{2} \mathrm{PbI}_{4}$ still lead to lower $J_{\mathrm{SC}}$ than that of control device. ${ }^{34}$ PEAI doped $\mathrm{PbI}_{2}$ film $\left(\mathrm{PEAI} / \mathrm{PbI}_{2}=0.05\right)$ was used to react with MAI to fabricate highly efficient 2D/3D PVSCs with a high efficiency of $19.10 \%,{ }^{35}$ while the low-pressure heating process need 2 hours and the particle size of the perovskite film is nonuniform. Recently, diethylammonium halogen ammonium salts $\left(\mathrm{DAX}, \mathrm{DA}^{+}=\right.$ $\left.\left(\mathrm{CH}_{3} \mathrm{CH}_{2}\right)_{2} \mathrm{NH}_{2}^{+}\right)$have been used to improve the morphology of the active layer in PVSCs. ${ }^{36,37}$ Recently, ammonium salt diethylammonium hydrochloride used as an additive enabled to accelerate the growth of the perovskite film. ${ }^{36}$ While, only diethylammonium hydrochloride added in the precursor solution keeps non-stoichiometric ratio, and diethylammonium hydrochloride can volatilize out from the film during the growth of perovskite crystal, introducing the uniformity of crystals, smoothness of film surface, and therefore, leading to low FF and PCE. Two-dimensional (2D) material diethylammonium bromide has also been used in our previous work to post treat $\mathrm{MAPbI}_{3}$ film, and Br element can induce the small crystals secondary grow into large crystals. ${ }^{37}$ However, the performances of the device with post-annealed film are partly depend on the performances of the $\mathrm{MAPbI}_{3}$ film which cause a lower short circuit current. It is worth mentioning that doping of DA cations into the perovskite precursor solution may be beneficial to improve the film morphology and increase the short circuit current of the devices. And $\mathrm{DA}^{+}$contains a short-branched chain than $\mathrm{PEA}^{+}$and $\mathrm{BA}^{+}$which may have better charge transport property and is able to introduce into the $\mathrm{MAPbI}_{3}$ perovskite to enhance the performance of the devices.

In this work, small quality of $2 \mathrm{D}$ perovskite $\mathrm{DA}_{2} \mathrm{PbI}_{4}$ (DAI is abbreviation for diethylammonium iodide, $\mathrm{DA}^{+}=\left(\mathrm{CH}_{3} \mathrm{CH}_{2}\right)_{2^{-}}$ $\mathrm{NH}_{2}^{+}$) has been incorporated with three-dimensional (3D) $\mathrm{MAPbI}_{3}$ in precursor solution, which facilitates the perovskite crystallization processes and improves the resulting film quality. The fabricated $\left(\mathrm{DA}_{2} \mathrm{PbI}_{4}\right)_{0.05} \mathrm{MAPbI}_{3}$ perovskite hybrid films exhibit good morphology with larger grains more than 1 micro and without pinhole. Compared with control device, incorporated $2 \mathrm{D}$ perovskites $\mathrm{DA}_{2} \mathrm{PbI}_{4}$ with long alkyl chain can increase long term stability of the device. Applying the mixed $\left(\mathrm{DA}_{2} \mathrm{PbI}_{4}\right)_{0.05} \mathrm{MAPbI}_{3}$ perovskite hybrid film in solar cells, the enhanced performance is achieved with a $V_{\mathrm{OC}}$ of $1.05 \mathrm{~V}$, shortcircuit current $\left(J_{\mathrm{SC}}\right)$ of $22.95 \mathrm{~mA} \mathrm{~cm} \mathrm{~cm}^{-2}$, and $\mathrm{FF}$ of $79.04 \%$, leading to a remarkable efficiency of $19.05 \%$, which is $20 \%$ higher than that of the control device $(15.73 \%)$.

\section{Results and discussion}

Fig. 1a and b illustrates the diagram and energy level of the planar perovskite solar cells used in this work. The perovskite layer was fabricated by antisolvent assisted deposition method. A small quantity of $2 \mathrm{D}$ material DAI was incorporated in $3 \mathrm{D}$ $\mathrm{MAPbI}_{3}$ with different compositions by mixing different amounts of $1.25 \mathrm{M}$ solution of $\mathrm{DAI}: \mathrm{PbI}_{2}$ (2:1) with the MAI : $\mathrm{PbI}_{2}$ precursor solution (DAI : $\mathrm{MAI}=7 \%, 10 \%$ and $15 \%$ molar ratio), and denoted as 7\%, 10\% and 15\% DAI contents for convenience. The chemical structure of DAI and schematic of DAI doped perovskite crystal are shown in Fig. 1c and d.
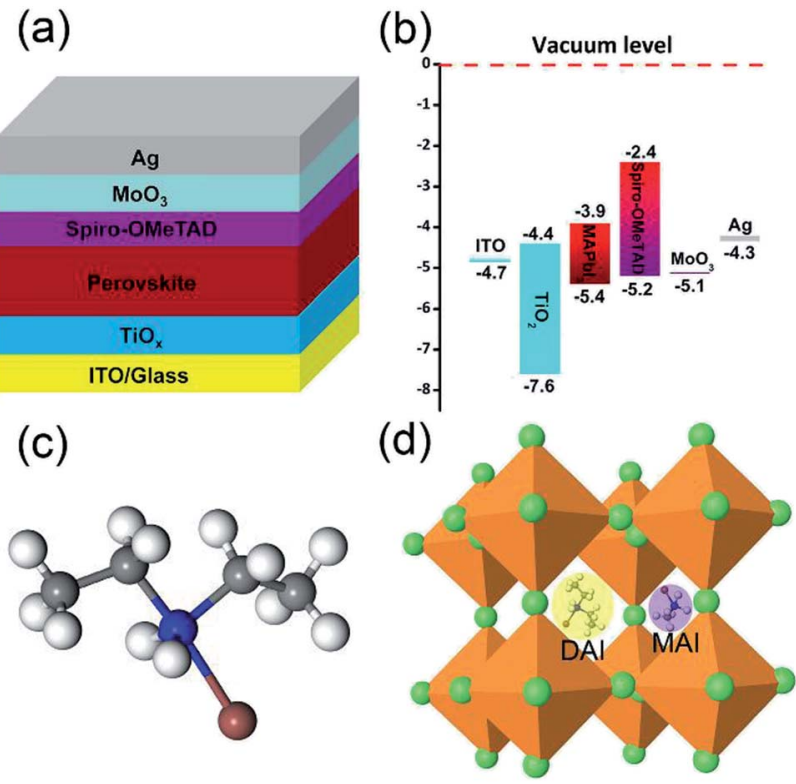

Fig. 1 Structure (a) and energy level (b) diagram of the inverted planar perovskite solar cell, the chemical structure of DAI (c) and schematic of DAl doped perovskite crystal (d).

The morphological evolution of perovskite films using various DA incorporation methods is shown in scanning electron microscopy (SEM) images (Fig. 2), indicating that incorporated DAI contents can positively facilitate the perovskite film grain growth. The morphology of the perovskite film without DAI was characterized by a poor-quality surface with small sized crystals about $161.54 \mathrm{~nm}$. When the DAI content is $7 \%$, the perovskite film presents larger grains with average grain size up to $0.71 \mu \mathrm{m}$. When the DAI content is $10 \%$, the grains size of perovskite film presents much larger grains about $1.27 \mu \mathrm{m}$, resulting in a much denser and more homogeneous morphology than the $\mathrm{MAPbI}_{3}$ film. When the DAI content is $15 \%$, the average grains size down to $1.00 \mu \mathrm{m}$. Generally, the larger the perovskite film crystals are, the better the solar cell performance is expected, because perovskite films with larger grains have lesser grain boundaries which act as barriers for charge transport between the cathode and anode in PVSCs. ${ }^{38,39}$ Therefore, from the SEM images, the 10\% DAI incorporated perovskite film may be the most suitable for high performance devices. The above results exhibit that incorporating small quality of DAI in $\mathrm{MAPbI}_{3}$ precursor solution can facilitate the film crystallization and produce larger grains with more homogeneous grain-size distribution, and 10\% DAI content can induce largest grain growth. Besides, in order to investigate whether other 2D cations incorporated can enlarge the perovskite grains, we also prepare the $10 \%$ PEAI and 10\% BAI doped perovskite films for comparison. The SEM images of 10\% PEAI and $10 \%$ BAI doped perovskite films are tested and displayed in Fig. S1. $\dagger$ It is obvious that the films doped with these two materials exhibit small grains less than $100 \mathrm{~nm}$, and even smaller than the $\mathrm{MAPbI}_{3}$ film. The result demonstrate that DA cation doped $3 \mathrm{D}$ perovskite can increase the film crystal grains is its unique properties. 

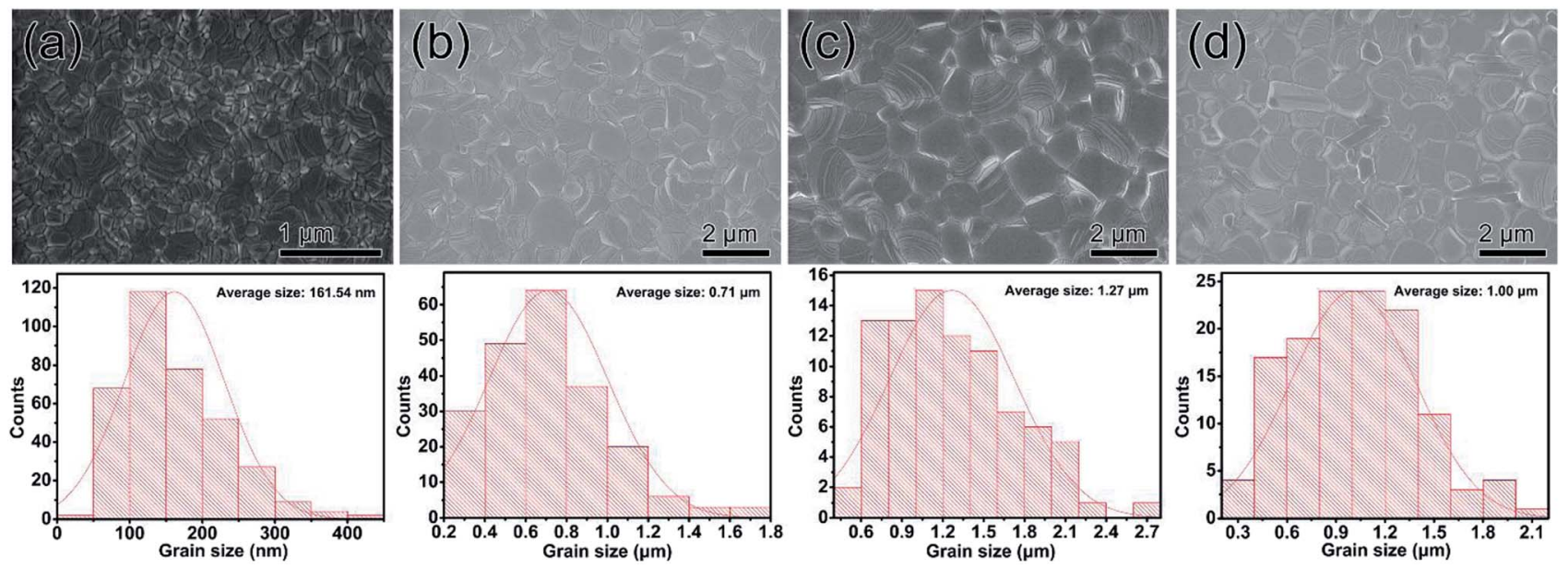

Fig. 2 Top view of SEM images and correspond grain size of perovskite films without DA (a) and with 7\% DAI content (b), 10\% DAI content (c) and $15 \%$ DAl content (d).

X-ray diffraction (XRD) analysis were carried out to identity a distinction of the perovskite films with different DAI contents, as shown in Fig. 3a. The MAPbI ${ }_{3}$ film exhibits the main characteristic diffraction peaks at the $2 \theta$ values of $14.13^{\circ}, 28.46^{\circ}$, and $31.90^{\circ}$ corresponding to the (110), (220), and (310) planes of tetragonal perovskite, respectively. The DA mixed perovskite film exhibits stronger diffusion peaks at (110) and (220) than those of DA free perovskite film, which reflects better crystallinity. Full width at half maximum (FWHM) of XRD peak corresponding to (110) plane is $0.08^{\circ}$ for the $7 \%$ and $10 \%$ DAI contents, which is narrower than that of the film without DAI $\left(0.10^{\circ}\right)$, however, the FWHM is widened to be $0.09^{\circ}$ for $15 \%$ DAI content. Those results indicate that the perovskite film incorporated $10 \%$ DAI content shown the best crystallinity. Furthermore, compared the XRD patterns of perovskite film of different DAI contents with the XRD patterns of $2 \mathrm{D}$ perovskite $\mathrm{DA}_{2} \mathrm{PbI}_{4}$ film in Fig. $\mathrm{S} 2, \uparrow$ it can be confirmed that the several peaks around $7.5^{\circ}$ in the XRD patterns of DA mixed films belong to $\mathrm{DA}_{2} \mathrm{PbI}_{4}$ and $\mathrm{DA}_{2} \mathrm{PbI}_{4}$ is successfully embedded in $\mathrm{MAPbI}_{3}$ film.

To investigate the effects of DAI doping into $\mathrm{MAPbI}_{3}$ on its optical properties, UV-visible absorption spectroscopy and steady-state photoluminescence (PL) spectra were measured as shown in Fig. 3b and c. Apparently, the absorption is improved with low DAI contents ( $7 \%$ and $10 \%$ ) and the absorption doesn't increase as the DAI content increases to $15 \%$. The perovskite film with $10 \%$ DAI content exhibits best absorption, which may be associate with the best film morphology. The absorption edge of the DA mixed perovskite films presents only a slightly blue shift compared with that of the DAI free film, which is consistent with the blue-shifted emission peak in the PL spectrum in Fig. 3c. As presented, the DAI free perovskite film shows a PL peak at $774 \mathrm{~nm}$, and DA incorporated perovskite films with $7 \%, 10 \%$ and 15\% DAI contents exhibit blue-shifted PL peaks at 768, 764 and $761 \mathrm{~nm}$. The slight shift to lower wavelength of the PL spectrum are probably due to the presence of $2 \mathrm{D}$ perovskite $\mathrm{DA}_{2} \mathrm{PbI}_{4}$.

The time-resolved PL (TRPL) spectra were measured with the incident exciting light at $401 \mathrm{~nm}$ to examine the effect of DAI contents on nonradiative recombination in the perovskite films.
The PL decay curves were fitted by the followed eqn (1) to evaluate the carrier recombination lifetime: ${ }^{\mathbf{4 0 , 4 1}}$

$$
\begin{gathered}
y=A+B_{1} \exp \left(-t / \tau_{1}\right)+B_{2} \exp \left(-t / \tau_{2}\right) \\
\tau_{\text {avg }}=\frac{\sum B_{i} \tau_{i}^{2}}{\sum B_{i} \tau_{i}}
\end{gathered}
$$

where $B_{1}$ and $B_{2}$ are the relative amplitudes, $\tau_{1}$ and $\tau_{2}$ are the lifetimes for the fast and slow recombination, respectively. ${ }^{42}$ The average PL lifetime of the carriers can be calculated by eqn $(2)^{43,44}$ and the detailed results are summarized in Table S3. $\dagger$ The DAI free film shows an averaged PL lifetime of $61.34 \mathrm{~ns}$, and the 7\%, $10 \%$ and $15 \%$ DA incorporated perovskite films exhibit averaged PL lifetimes of 72.65 ns, 89.48 ns, 35.65 ns, respectively. On the basis of the TRPL spectroscopic characterization, perovskite films with low DAI contents present longer carrier lifetimes, suggest a significant drop in non-radiative recombination due to larger perovskite crystal grains which is consistent with the SEM images. However, the PL lifetime of perovskite with $15 \%$ DAI content was shortened which may be two reasons: one is the decrease in film crystallinity, and the other is excessive 2D perovskite exist in 3D perovskite as more 2D perovskite (lower $n$ value) leads to shorter lifetime of perovskite in the literatures. ${ }^{31,45}$ The SEM image of 15\% DAI incorporated perovskite shows that there are some micron rods appeared, we speculate that phase separation may occur due to more $2 \mathrm{D}$ perovskite doped in $3 \mathrm{D}$ perovskite, and PL quenched by the 2D perovskite which supports the notion of hole transfer from 3D perovskite into 2D perovskite. From the above results, the longest lifetime of the PL transition in the $\left(\mathrm{DA}_{2} \mathrm{PbI}_{4}\right)_{0.05} \mathrm{MAPbI}_{3}$ perovskite film may be attributed to the decrease in the concentration of defects and the increase in crystallinity, which are matched with the SEM and XRD results, ${ }^{46}$ indicating that high-quantity film can suppress nonradiative charge carrier recombination.

Considering large grains, well crystallinity and long lifetime of DAI incorporated films, current-voltage $(J-V)$ measurements were employed to directly observe the effects of DAI contents on device performance. The $J-V$ characteristics of the optimal 

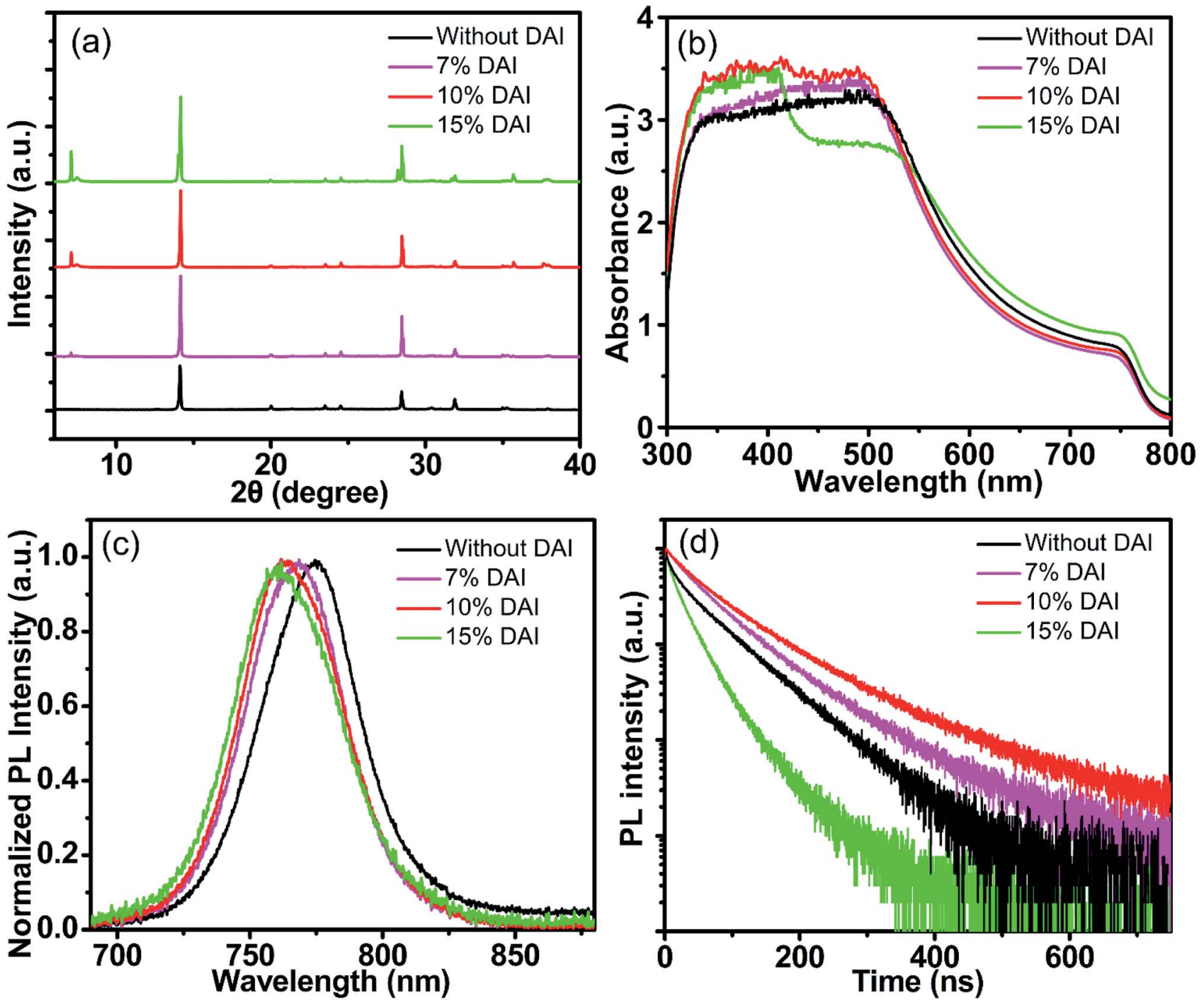

Fig. 3 X-ray diffraction patterns (a), UV-vis absorption spectra (b), PL spectra (c) and TRPL spectra (d) of perovskite films without and with 7\%, 10\% and $15 \%$ DAl contents.

devices with the DAI free and DAI mixed perovskite film under AM 1.5G illumination $\left(100 \mathrm{~mW} \mathrm{~cm}^{-2}\right)$ are shown in Fig. S3, $\dagger$ and the detailed device parameters are summarized in Table $\mathrm{S} 1 . \dagger$ It is interesting to see that the $V_{\mathrm{OC}}$ does not increase as the DAI content increases, which is different from the case of quasi2D $\mathrm{PEA}_{2} \mathrm{MA}_{n-1} \mathrm{~Pb}_{n} \mathrm{I}_{3 n+1} \cdot{ }^{30,34}$ And the SEM image shows that the micron rods appeared on the surface of $15 \%$ DAI film, indicating the structural mismatch lead to different phases. These results illustrate that a small amount of $2 \mathrm{D} \mathrm{D}_{2} \mathrm{PbI}_{4}$ is not incorporated into the crystal lattice of $3 \mathrm{D} \mathrm{MAPbI}_{3}$ ascribe to the structural mismatch that possibly exists at the grain boundaries. The device based on the perovskite film with $10 \%$ DAI content shows the best PCE. Obviously, the device with the $\left(\mathrm{DA}_{2} \mathrm{PbI}_{4}\right)_{0.05} \mathrm{MAPbI}_{3}$ perovskite film yields a significant enhancement in performance compared to the control device as shown in Fig. 4a and Table 1, mainly originating from a markedly enhanced $\mathrm{FF}$ from $68.60 \%$ to $79.04 \%$, as well as a slightly increased $J_{\mathrm{SC}}$ from $22.47 \mathrm{~mA} \mathrm{~cm}^{-1}$ to $22.95 \mathrm{~mA} \mathrm{~cm}^{-1}$ and $V_{\mathrm{OC}}$ from $1.02 \mathrm{~V}$ to $1.05 \mathrm{~V}$, leading to an overall PCE from $15.73 \%$ to
$19.05 \%$. The improved electronic properties of the device with the $\left(\mathrm{DA}_{2} \mathrm{PbI}_{4}\right)_{0.05} \mathrm{MAPbI}_{3}$ perovskite film are normally ascribe to the large grains and less grain boundaries. $J-V$ curves and statistical data of reverse and forward scanning are described in Fig. S4 and Table S2. $\dagger$ The $J-V$ curves of $\mathrm{MAPbI}_{3}$ device yielded relatively high hysteresis. While, the hysteresis of the $\left(\mathrm{DA}_{2}-\right.$ $\left.\mathrm{PbI}_{4}\right)_{0.05} \mathrm{MAPbI}_{3}$ perovskite solar cell is reduced compared with the DAI free device, which mainly attributed to increased grain size and decreased grain boundaries defects of the perovskite film. ${ }^{47}$

The incident photon-to-current efficiency (IPCE) spectra of the corresponding devices were measured, as shown in Fig. 4b. The $\left(\mathrm{DA}_{2} \mathrm{PbI}_{4}\right)_{0.05} \mathrm{MAPbI}_{3}$ device exhibits a substantial enhancement in a broad wavelength range from $400 \mathrm{~nm}$ to $750 \mathrm{~nm}$ relative to the control device, which is consistent with the improvement in morphology and the increase in absorption. In addition, the value of the integrated photocurrent density from the IPCE for the solar spectrum is in well agreement with the obtained $J_{\mathrm{SC}}$. The output short-circuit 

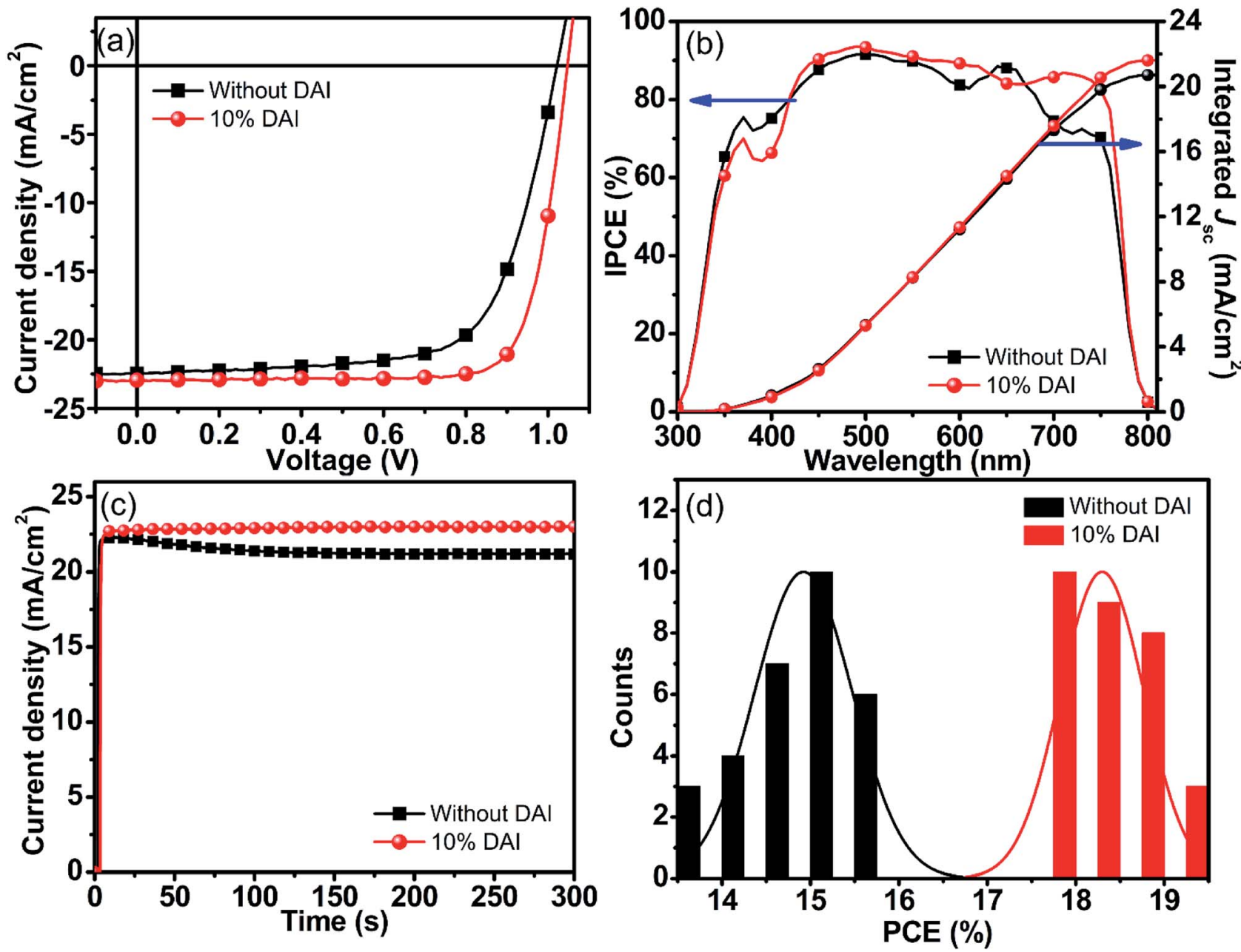

Fig. $4 J-V$ characteristics (a), EQE spectra (b), stabilized short-circuit photocurrent density (c), and PCE distribution (d) of the perovskite devices without and with $10 \%$ DAl contents.

Table 1 Performance of devices with perovskite films without and with $10 \%$ DAl contents. The values inside the parentheses are average values obtained from 30 devices, respectively

\begin{tabular}{lllll}
\hline Active layer & $J_{\mathrm{SC}}\left(\mathrm{mA} \mathrm{cm}^{-2}\right)$ & $V_{\mathrm{OC}}(\mathrm{V})$ & $\mathrm{FF}(\%)$ & \multicolumn{1}{c}{ PCE $(\%)$} \\
\hline Champion-MAPbI $_{3}$ & 22.47 & 1.02 & 68.60 & $(66.64 \pm 1.82)$ \\
MAPbI $_{3}$ perovskite & $(21.98 \pm 0.48)$ & $(1.02 \pm 0.01)$ & 79.04 & $(14.92 \pm 0.54)$ \\
Champion-DA doped & 22.95 & 1.05 & $(78.00 \pm 1.65)$ & $(1.04 \pm 0.02)$
\end{tabular}

photocurrent of the cells as a function of time were recorded, as shown in Fig. 4c. For the control device, the photocurrent is continuous decreased for the first $200 \mathrm{~s}$, indicating that the device is unstable, which may be ascribe to the more traps in the perovskite film. While for the $\left(\mathrm{DA}_{2} \mathrm{PbI}_{4}\right)_{0.05} \mathrm{MAPbI}_{3}$ devices, the photocurrent stabilizes within seconds to approximately 22.95 $\mathrm{mA} \mathrm{cm}^{-2}$, which is comparable to the device parameters extracted from the $J-V$ curve. The results proved that the $\left(\mathrm{DA}_{2}-\right.$ $\left.\mathrm{PbI}_{4}\right)_{0.05} \mathrm{MAPbI}_{3}$ device better output stability which may be ascribed to the DAI induced large grains with less traps in the perovskite film. Fig. 4d displays the PCE distribution of the control devices and the $\left(\mathrm{DA}_{2} \mathrm{PbI}_{4}\right)_{0.05} \mathrm{MAPbI}_{3}$ devices calculated from 30 devices, respectively. In general, the
$\left(\mathrm{DA}_{2} \mathrm{PbI}_{4}\right)_{0.05} \mathrm{MAPbI}_{3}$ devices exhibit an average PCE of $18.30 \%$, which shows the good reproducibility for the $\left(\mathrm{DA}_{2} \mathrm{PbI}_{4}\right)_{0.05^{-}}$ $\mathrm{MAPbI}_{3}$ devices. Furthermore, we have also measured the long-
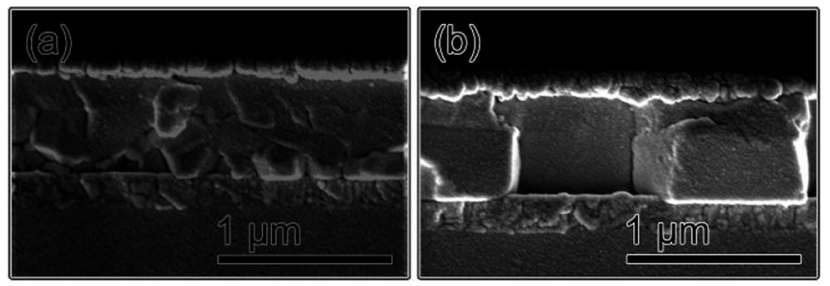

Fig. 5 Cross-section SEM images of perovskite films without (a) and with $10 \%$ DAl content (b). 

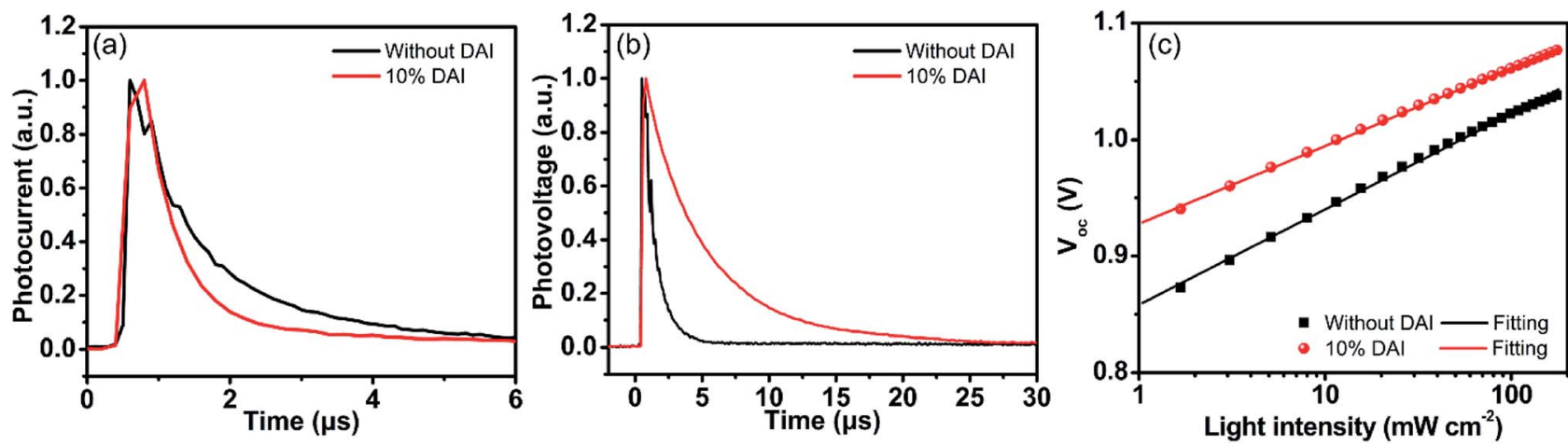

Fig. 6 Transient photocurrent (a), transient photovoltage (b) and LIPV characteristics (c) of the perovskite devices without and with 10\% DAI content.

term stability of the devices with DAI free perovskite film and $\left(\mathrm{DA}_{2} \mathrm{PbI}_{4}\right)_{0.05} \mathrm{MAPbI}_{3}$ film which are storage in the glove box as shown in Fig. S5. $\dagger$ The PCE of the $\left(\mathrm{DA}_{2} \mathrm{PbI}_{4}\right)_{0.05} \mathrm{MAPbI}_{3}$ device maintains almost $80 \%$ of the initial PCE after 60 days, showing better stability than the $\mathrm{MAPbI}_{3}$ device.

The cross-sectional SEM images of the $\mathrm{MAPbI}_{3}$ and $\left(\mathrm{DA}_{2}-\right.$ $\left.\mathrm{PbI}_{4}\right)_{0.05} \mathrm{MAPbI}_{3}$ devices are shown in Fig. 5a and b. The perovskite layers are about $400 \mathrm{~nm}$ thick for both devices. It can be seen that the grains in the $\mathrm{MAPbI}_{3}$ device are about 100$300 \mathrm{~nm}$ and there are about two or more grains between the electronic transport layer and hole transport layer, which will bring out defects recombination. For the $\left(\mathrm{DA}_{2} \mathrm{PbI}_{4}\right)_{0.05} \mathrm{MAPbI}_{3}$ device, the grains are large enough that most of the photogenerated charges can be collected by the electrodes without encountering grain boundaries, which can significantly decrease charge recombination loss and enhance the charge transport and carrier extraction. Meanwhile, the decreased grain boundary density might diminish the amount of boundary traps and bring about a reduction of defects recombination.

To further explore the origin of the improved device characteristics, transient photocurrent (TPC) and transient photovoltage (TPV) techniques were carried out to further investigate the charge extraction and carrier recombination lifetimes in the working device. ${ }^{48,49}$ TPC was generated by a nanosecond pulse of a laser incident on devices and could provide insightful information on charge transport within the device. As shown in Fig. $6 \mathrm{a},\left(\mathrm{DA}_{2} \mathrm{PbI}_{4}\right)_{0.05} \mathrm{MAPbI}_{3}$ based device shows a faster decay of $0.51 \mu \mathrm{s}$ compared with that of the control device $(1.08 \mu \mathrm{s})$, which confirms the $\left(\mathrm{DA}_{2} \mathrm{PbI}_{4}\right)_{0.05} \mathrm{MAPbI}_{3}$ device has quicker charge transport and charge extraction. ${ }^{18} \mathrm{TPV}$, correlating to the electron lifetime in the active layer, provides an insight into carrier recombination in the cell. TPV measurement was performed with a pulsed laser under 1 sun illumination intensity at open-circuit voltage condition. As shown in Fig. 6b, the chargerecombination lifetime of the $\left(\mathrm{DA}_{2} \mathrm{PbI}_{4}\right)_{0.05} \mathrm{MAPbI}_{3}$ device is $4.47 \mu \mathrm{s}$, much longer than $1.01 \mu \mathrm{s}$ which is calculated from the control device. The longer carrier lifetime in the $\left(\mathrm{DA}_{2} \mathrm{PbI}_{4}\right)_{0.05^{-}}$ $\mathrm{MAPbI}_{3}$ device indicates that carrier recombination has been suppressed due to the better film quality.

The open-circuit voltage as a function of light illumination intensities (LIPV) measurement was also performed to gain insight into the influence of traps on recombination under the open-circuit condition, as shown in Fig. 6c. The ideality factor $(n)$ of PVSCs can be calculated according to equation:

$$
n=\frac{q}{k T} \frac{\mathrm{d} V_{\text {oc }}}{\mathrm{d} \ln (I)}
$$

where $q$ is the elementary charge and $k T$ relates to the thermal energy. In general, the $n$ value ranges from 1 to 2 in a solar cell. ${ }^{50}$ The $n$ value for the $\left(\mathrm{DA}_{2} \mathrm{PbI}_{4}\right)_{0.05} \mathrm{MAPbI}_{3}$ device is $1.15 \pm 0.01$ lower than $1.38 \pm 0.01$ for the control device, revealing that the contribution of trap-assisted recombination is smaller in the $\left(\mathrm{DA}_{2} \mathrm{PbI}_{4}\right)_{0.05} \mathrm{MAPbI}_{3}$ device. The good crystallization of $\left(\mathrm{DA}_{2}-\right.$ $\left.\mathrm{PbI}_{4}\right)_{0.05} \mathrm{MAPbI}_{3}$ perovskite film can form better contact with the hole/electron transport layers and lead to fewer interfacial defects restrain the trap-assisted recombination effectively.

\section{Conclusions}

In a summary, $2 \mathrm{D}$ perovskite $\mathrm{DA}_{2} \mathrm{PbI}_{4}$ was first incorporated into the 3D MAPbI 3 perovskite to improve the crystallization of perovskite thin films. A significantly enhanced PCE $(\sim 20 \%)$ of the planar perovskite solar cells is achieved from $15.73 \%$ to $19.05 \%$. SEM images and XRD spectra evidence that incorporated $2 \mathrm{D} \mathrm{DA}_{2} \mathrm{PbI}_{4}$ can facilitate homogenous crystal growth for better morphology and well crystallinity with large grains and uniform grains size. The grain size is large enough to throughout the device that can decrease charge loss by recombination at grain boundaries, which is also responsible for the improved performance. TRPL spectra were used to extract charge carrier dynamics, demonstrating an exceptional improvement in carrier lifetime for $\left(\mathrm{DA}_{2} \mathrm{PbI}_{4}\right)_{0.05} \mathrm{MAPbI}_{3}$ film. The DAI doped perovskite film can effectively suppress trapassisted recombination and enhance the charge extraction, which is evidenced from the TPC, LIPV and TPV measurements. This work provides an approach to obtain large grain perovskite films for high efficiency and stable perovskite solar cells.

\section{Experimental}

\section{Device fabrication}

$\mathrm{PbI}_{2}$ (99.999\%), $\mathrm{MoO}_{3}(99.998 \%)$ and $\mathrm{Ag}(99.99 \%)$ are purchased from Alfa Aesar. MAI and DAI are purchased from dyesol. Spiro- 
OMeTAD (99\%) are purchased from 1-materials. The ITO substrates $\left(15 \Omega \mathrm{sq}^{-1}\right)$ were firstly cleaned in an ultrasonic bath by detergent, deionized water, acetone, and ethanol for $30 \mathrm{~min}$ each. Subsequently, the ITO substrates were exposed to $\mathrm{UV}^{-\mathrm{O}_{3}}$ plasma for $10 \mathrm{~min}$. $\mathrm{TiO}_{x}$ solution which were synthesized according to our previous work ${ }^{27}$ were deposited onto glass/ITO substrates with spin-coating speed at $7000 \mathrm{rpm}$ for $40 \mathrm{~s}$ in ambient condition. The substrates were then annealed on a hot plate in ambient air at $150{ }^{\circ} \mathrm{C}$ for $40 \mathrm{~min}$. The ITO substrates coated with the $\mathrm{TiO}_{x}$ layers were transferred into a nitrogenfilled glove box. Subsequently, a $1.25 \mathrm{mM}$ solution of $\mathrm{MAPbI}_{3}$ $\left(\mathrm{PbI}_{2}: \mathrm{CH}_{3} \mathrm{NH}_{3} \mathrm{I}=1: 1\right)$ in DMF was deposited onto TiO ${ }_{x}$ layers by a one-step solvent induced method with the spin-coating process at $3000 \mathrm{rpm}$ for $12 \mathrm{~s}$ followed by $5000 \mathrm{rpm}$ for $30 \mathrm{~s}$. During the low-speed step, $150 \mu$ l chlorobenzene was dropcasted on the rotating substrates after $8 \mathrm{~s}$ of spinning to promote crystallization. $\mathrm{DA}_{2} \mathrm{PbI}_{4}$ was incorporated in $3 \mathrm{D}$ $\mathrm{MAPbI}_{3}$ with different compositions by mixing different amounts of $1.25 \mathrm{M}$ solution of $\mathrm{DAI}: \mathrm{PbI}_{2}(2: 1)$ with the MAI : $\mathrm{PbI}_{2}$ precursor solution (7\%, 10\% and 15\% molar ratio). All the perovskite films were annealed at $100{ }^{\circ} \mathrm{C}$ for $10 \mathrm{~min}$ to form crystal film. After cooling down, $30 \mu \mathrm{l}$ of spiro-OMeTAD solution were spin coated on the $\mathrm{MAPbI}_{3}$ layers at $4000 \mathrm{rpm}$ for $30 \mathrm{~s}$. Finally, about $10 \mathrm{~nm} \mathrm{MoO}_{3}$ and $90 \mathrm{~nm} \mathrm{Ag}$ were deposited on the tops of the spiro-OMeTAD-coated film at a constant evaporation rate of $0.1 \AA^{-1}$ and $1 \AA \mathrm{s}^{-1}$, respectively. The active area of all the devices is $4.5 \mathrm{~mm}^{2}$.

\section{Film characterization}

The morphologies of the perovskite films were investigated using a field emission scanning electron microscope (ZEISS GeminiSEM 300). The XRD patterns were tested with a Bruker D8 Advance X-ray diffractometer. The absorption spectra were measured using an UV-vis absorption spectrophotometer (Shimadzu UV-3101PC). The PL spectra of the perovskite films were examined using Fluorolog, Horiba Scientific. TRPL decay profiles of ITO/perovskite films detected by HORIBA JOBIN YVON using a $401 \mathrm{~nm}$ laser.

\section{Device characterization}

$J-V$ characteristics were measured using a solar simulator (SANEI Electric, XEC-301S) equipped with a Keithley 6430 Source meter under Air Mass $1.5 \mathrm{G}$ illumination at $100 \mathrm{~mW} \mathrm{~cm}{ }^{-2}$. The IPCE measurements were performed on a solar cell QE/IPCE measurement system (Zolix Solar Cell Scan 100). TPC and TPV measurements were conducted using a digital oscilloscope (Tektronix MSO 5104B), excitated by a Q-switched neodymium ion-doped yttrium aluminum garnet $\left(\mathrm{Nd}^{3+}\right.$ :YAG) laser. To form the short-circuit and open-circuit conditions, the input impedance of the oscilloscope was set to $50 \Omega$ and $1 \mathrm{M} \Omega$, respectively. The TPV measurement was carried out under 1 sun background illumination, with a laser pulse used to produce a small perturbation. The LIPV measurements were carried out using a focused cool white light emitting diodes (LEDs), for which illumination intensities were adjusted with a GPIB-controlled power. The $V_{\text {OC }}$ values were collected by a 16 bits data acquisition board (NI-6052E).

\section{Conflicts of interest}

There are no conflicts to declare.

\section{Acknowledgements}

This work was supported by the Fundamental Research Funds for the Central Universities (Grant No. 2018YJS183), and The National Key Research and Development Program of China (Grant No. 2016YFB0700703) and National Natural Science Foundation of China (Grant No. 51603010, 61775011, 61735004, 61674012, 61875009 and 61675018).

\section{Notes and references}

1 A. Kojima, K. Teshima, Y. Shirai and T. Miyasaka, J. Am. Chem. Soc., 2009, 131, 6050-6051.

2 J. H. Im, C. R. Lee, J. W. Lee, S. W. Park and N. G. Park, Nanoscale, 2011, 3, 4088-4093.

3 W. S. Yang, J. H. Noh, N. J. Jeon, Y. C. Kim, S. Ryu, J. Seo and S. I. Seok, Science, 2015, 348, 1234.

4 N. J. Jeon, J. H. Noh, W. S. Yang, Y. C. Kim, S. Ryu, J. Seo and S. I. Seok, Nature, 2015, 517, 476-480.

5 J. H. Noh, S. H. Im, J. H. Heo, T. N. Mandal and S. I. Seok, Nano Lett., 2013, 13, 1764-1769.

6 M. M. Lee, J. Teuscher, T. Miyasaka, T. N. Murakami and H. J. Snaith, Science, 2012, 338, 643-647.

7 Y. Ogomi, A. Morita, S. Tsukamoto, T. Saitho, N. Fujikawa, Q. Shen, T. Toyoda, K. Yoshino, S. S. Pandey, T. Ma and S. Hayase, J. Phys. Chem. Lett., 2014, 5, 1004-1011.

8 P. W. Liang, C. Y. Liao, C. C. Chueh, F. Zuo, S. T. Williams, X. K. Xin, J. Lin and A. K. Jen, Adv. Mater., 2014, 26, 37483754 .

9 D. Bi, C. Yi, J. Luo, J.-D. Décoppet, F. Zhang, S. M. Zakeeruddin, X. Li, A. Hagfeldt and M. Grätzel, Nat. Energy, 2016, 1, 16142.

10 NREL Chart, https://www.nrel.gov/pv/assets/pdfs/pvefficiency-chart.20181214.pdf.

11 W. E. I. Sha, X. Ren, L. Chen and W. C. H. Choy, Appl. Phys. Lett., 2015, 106, 221104.

12 J. You, Z. Hong, Y. Yang, Q. Chen, M. Cai, T.-B. Song, C.-C. Chen, S. Lu, Y. Liu, H. Zhou and Y. Yang, ACS Nano, 2014, 8, 1674-1680.

13 N. J. Jeon, J. H. Noh, Y. C. Kim, W. S. Yang, S. Ryu and S. I. Seok, Nat. Mater., 2014, 13, 897-903.

14 J. Burschka, N. Pellet, S. J. Moon, R. Humphry-Baker, P. Gao, M. K. Nazeeruddin and M. Gratzel, Nature, 2013, 499, 316319.

15 M. Liu, M. B. Johnston and H. J. Snaith, Nature, 2013, 501, 395-398.

16 Y. Deng, E. Peng, Y. Shao, Z. Xiao, Q. Dong and J. Huang, Energy Environ. Sci., 2015, 8, 1544-1550.

17 T. Li, Y. Pan, Z. Wang, Y. Xia, Y. Chen and W. Huang, J. Mater. Chem. A, 2017, 5, 12602-12652. 
18 Z. Xiao, Q. Dong, C. Bi, Y. Shao, Y. Yuan and J. Huang, Adv. Mater., 2014, 26, 6503-6509.

19 J.-W. Lee, S.-H. Bae, Y.-T. Hsieh, N. De Marco, M. Wang, P. Sun and Y. Yang, Chem, 2017, 3, 290-302.

20 X. Gong, M. Li, X.-B. Shi, H. Ma, Z.-K. Wang and L.-S. Liao, Adv. Funct. Mater., 2015, 25, 6671-6678.

21 M. Li, Y.-H. Chao, T. Kang, Z.-K. Wang, Y.-G. Yang, S.-L. Feng, Y. Hu, X.-Y. Gao, L.-S. Liao and C.-S. Hsu, J. Mater. Chem. A, 2016, 4, 15088-15094.

22 L. Zuo, H. Guo, D. W. deQuilettes, S. Jariwala, N. De Marco, S. Dong, R. DeBlock, D. S. Ginger, B. Dunn, M. Wang and Y. Yang, Sci. Adv., 2017, 3, e1700106.

23 J.-Y. Seo, T. Matsui, J. Luo, J.-P. Correa-Baena, F. Giordano, M. Saliba, K. Schenk, A. Ummadisingu, K. Domanski, M. Hadadian, A. Hagfeldt, S. M. Zakeeruddin, U. Steiner, M. Grätzel and A. Abate, Adv. Energy Mater., 2016, 6, 1600767.

24 H.-L. Hsu, C.-C. Chang, C.-P. Chen, B.-H. Jiang, R.-J. Jeng and C.-H. Cheng, J. Mater. Chem. A, 2015, 3, 9271-9277.

25 Y. Chen, Y. Sun, J. Peng, W. Zhang, X. Su, K. Zheng, T. Pullerits and Z. Liang, Adv. Energy Mater., 2017, 7, 1700162.

26 G. Grancini, C. Roldan-Carmona, I. Zimmermann, E. Mosconi, X. Lee, D. Martineau, S. Narbey, F. Oswald, F. De Angelis, M. Graetzel and M. K. Nazeeruddin, Nat. Commun., 2017, 8, 15684.

27 B.-E. Cohen, M. Wierzbowska and L. Etgar, Sustainable Energy Fuels, 2017, 1, 1935-1943.

28 I. C. Smith, E. T. Hoke, D. Solis-Ibarra, M. D. McGehee and H. I. Karunadasa, Angew. Chem., Int. Ed. Engl., 2014, 53, 11232-11235.

29 D. H. Cao, C. C. Stoumpos, O. K. Farha, J. T. Hupp and M. G. Kanatzidis, J. Am. Chem. Soc., 2015, 137, 7843-7850.

30 L. N. Quan, M. Yuan, R. Comin, O. Voznyy, E. M. Beauregard, S. Hoogland, A. Buin, A. R. Kirmani, K. Zhao, A. Amassian, D. H. Kim and E. H. Sargent, J. Am. Chem. Soc., 2016, 138, 2649-2655.

31 H. Zheng, G. Liu, L. Zhu, J. Ye, X. Zhang, A. Alsaedi, T. Hayat, X. Pan and S. Dai, Adv. Energy Mater., 2018, 8, 1800051.

32 H. Tsai, W. Nie, J. C. Blancon, C. C. Stoumpos, R. Asadpour, B. Harutyunyan, A. J. Neukirch, R. Verduzco, J. J. Crochet, S. Tretiak, L. Pedesseau, J. Even, M. A. Alam, G. Gupta, J. Lou, P. M. Ajayan, M. J. Bedzyk and M. G. Kanatzidis, Nature, 2016, 536, 312-316.
33 Z. Wang, Q. Lin, F. P. Chmiel, N. Sakai, L. M. Herz and H. J. Snaith, Nat. Energy, 2017, 6, 17135.

34 J. Chen, D. Lee and N. G. Park, ACS Appl. Mater. Interfaces, 2017, 9, 36338-36349.

35 M. H. Li, H. H. Yeh, Y. H. Chiang, U. S. Jeng, C. J. Su, H. W. Shiu, Y. J. Hsu, N. Kosugi, T. Ohigashi, Y. A. Chen, P. S. Shen, P. Chen and T. F. Guo, Adv. Mater., 2018, 30, e1801401.

36 Y. Wang, N. Song, L. Feng and X. Deng, ACS Appl. Mater. Interfaces, 2016, 8, 24703-24711.

37 X. Huang, W. Bi, P. Jia, Y. Tang, Z. Lou, Y. Hu, Q. Cui, Y. Hou and F. Teng, Org. Electron., 2019, 67, 101-108.

38 C. Bi, Q. Wang, Y. Shao, Y. Yuan, Z. Xiao and J. Huang, Nat. Commun., 2015, 6, 7747.

39 Y. Shao, Y. Fang, T. Li, Q. Wang, Q. Dong, Y. Deng, Y. Yuan, H. Wei, M. Wang, A. Gruverman, J. Shield and J. Huang, Energy Environ. Sci., 2016, 9, 1752-1759.

40 Q. Han, S. H. Bae, P. Sun, Y. T. Hsieh, Y. M. Yang, Y. S. Rim, H. Zhao, Q. Chen, W. Shi, G. Li and Y. Yang, Adv. Mater., 2016, 28, 2253-2258.

41 H. Si, Q. Liao, Z. Kang, Y. Ou, J. Meng, Y. Liu, Z. Zhang and Y. Zhang, Adv. Funct. Mater., 2017, 27, 1701804.

42 P. Chen, Y. Bai, S. Wang, M. Lyu, J.-H. Yun and L. Wang, Adv. Funct. Mater., 2018, 1706923, DOI: 10.1002/adfm.201706923.

43 X. Xu, C. Ma, Y. Cheng, Y.-M. Xie, X. Yi, B. Gautam, S. Chen, H.-W. Li, C.-S. Lee, F. So and S.-W. Tsang, J. Power Sources, 2017, 360, 157-165.

44 D. Zhao, Y. Yu, C. Wang, W. Liao, N. Shrestha, C. R. Grice, A. J. Cimaroli, L. Guan, R. J. Ellingson, K. Zhu, X. Zhao, R.-G. Xiong and Y. Yan, Nat. Energy, 2017, 2, 17018.

45 D. Ramirez, K. Schutt, Z. Wang, A. J. Pearson, E. Ruggeri, H. J. Snaith, S. D. Stranks and F. Jaramillo, ACS Energy Lett., 2018, 3, 2246-2251.

46 N. De Marco, H. Zhou, Q. Chen, P. Sun, Z. Liu, L. Meng, E. P. Yao, Y. Liu, A. Schiffer and Y. Yang, Nano Lett., 2016, 16, 1009-1016.

47 Y. Shao, Z. Xiao, C. Bi, Y. Yuan and J. Huang, Nat. Commun., 2014, 5, 5784.

48 H. Zhou, Q. Chen, G. Li, S. Luo, T.-b. Song, H.-S. Duan, Z. Hong, J. You, Y. Liu and Y. Yang, Science, 2014, 345, 542. 49 Q. Jiang, L. Zhang, H. Wang, X. Yang, J. Meng, H. Liu, Z. Yin, J. Wu, X. Zhang and J. You, Nat. Energy, 2016, 2, 16177.

50 T. Kirchartz, F. Deledalle, P. S. Tuladhar, J. R. Durrant and J. Nelson, J. Phys. Chem. Lett., 2013, 4, 2371-2376. 